\title{
Evaluation of Calcaneal Fractures by Multi Detector CT and Its Significant Effect on the Surgical Management Planning
}

Alia Abd Allah El Fiky, Remon Zaher Elia, Amir Louis Louka, Doaa Sobhy Aneis

Department of radiodiagnosis, Faculty of Medicine, Ain Shams University

\begin{abstract}
Background: Familiarity with the normal calcaneal anatomy is important for understanding fracture mechanisms and classification schemes. Clinical presentation at the time of evaluation generally includes (a) a history of a fall from a height, and (b) certain signs that aid the physician in identifying possible calcaneal fractures.

Purpose: To look at the role played by the multi detector computed tomography (MDCT) in assessing calcaneus fractures and delineate the fracture fragment which help in decision making in the management of extra and intra articular fractures of the calcaneum and pre-operative planning.

Patients and Methods: This study will be conducted on patients with calcaneal fractures suspected clinically or by $\mathrm{x}$ ray diagnosis. The patient will be referred from orthopaedic department at Ain Shams University Hospitals; the patient will be investigated using MDCT.

Results: This study included 44 feet of 41 patients (three bilateral); 35 males and 6 females, representing $85.4 \%$ and $14.6 \%$ of all patients respectively, their mean age was 34.22 years, we observed that calcaneal fractures commonly occur in male than female.

Conclusion: Multi detector CT is the best method of assessing calcaneus fracture in order to decide management. It delineates the fracture fragments and help in making the pre-operative planning of the fracture.
\end{abstract}

Keywords: Computed tomography, calcaneal fracture, Sanders classification, musculoskeletal

\section{INTRODUCTION}

The calcaneus is the largest and most commonly fractured of the tarsal bones. Calcaneal fractures represent only about $2 \%$ of all fractures but $\mathbf{6 0 \%}$ of fractures involving the tarsal bones ${ }^{(\mathbf{1})}$.

Familiarity with the normal calcaneal anatomy is important for understanding fracture mechanisms and classification schemes. Clinical presentation at the time of evaluation generally includes $(a)$ a history of a fall from a height, and (b) certain signs that aid the physician in identifying possible calcaneal fractures ${ }^{(2)}$.

Modern calcaneal fracture classification systems rely heavily on computed tomography (CT) because of its three-dimensional approach, rather than on two-dimensional conventional radiography as was used in the past. Use of multidetector CT has allowed the development of classification systems that correlate with management ${ }^{(\mathbf{1})}$.

The Sanders classification system is the most commonly used system for describing intra articular fractures of the calcaneus, which account for the majority of calcaneal fractures. Extra articular fractures are classified according to a tripartite anatomic division of the calcaneal surface. Treatment can be either surgical or conservative depending on the radiologic classification of the fracture ${ }^{(2)}$.
Familiarity with calcaneal anatomy and fracture patterns is essential for radiologists to guide the treating physicians ${ }^{(2)}$.

\section{PATIENTS AND METHODS}

This study was conducted on patients with calcaneal fractures suspected clinically or by $\mathrm{x}$ ray diagnosis. The patients were referred from orthopaedic department at Ain Shams University Hospitals; the patients were investigated using MDCT.

\section{Study place:}

Ain Shams University Hospitals. The study was approved by the Ethics Board of Ain Shams University and an informed written consent was taken from each participant in the study.

Sample size: 41 patients

Equipment used: MDCT, 80 slice Toshiba machine

Inclusion criteria: Age group: any age. Both sexes are included. Trauma patients suspected to have calcaneal fracture by history and clinical examination or by $\mathrm{x}$ ray examination.

Exclusion criteria: Previous calcaneal surgery that might have altered the normal anatomy, pregnant women.

All patients will be clinically assessed

by: Clinical history. Physical examination. 
MDCT examination. (64 slice Toshiba machine).

CT scan: CT scan of the calcaneus was obtained with 80-channel CT scanner (Toshiba), we imaged the hind foot with $0.625-\mathrm{mm}$ collimation, a pitch of $0.5625,130 \mathrm{kV}$, and 60 $\mathrm{mA}$. The CT scan was obtained with the patient lying supine in the scanner with the knee flexed and the foot as plantigrade as the patient was allowed. Both feet were imaged simultaneously. For comparison purposes we kept the feet as well aligned as possible so the eventual images were matched side by side. Reconstruction CT planes were obtained in $0.5 \mathrm{~mm}$ slice thickness, we used the ankle joint on the axial images as reference to obtain true sagittal and coronal planes of the hind foot. For Sanders classification the axial and coronal images were reformatted parallel and perpendicular to the anatomic posterior facet of the sagittally reconstructed images.

\section{Classification of the intra articular calcaneal fracture was obtained according to Sanders classification into:}

Type- 1 fractures, in which the articular fragments are displaced less than $2 \mathrm{~mm}$ relative to one another.

Type-2 fractures, in which there are two articular fragments.

Type-3 fractures, in which there are three articular fragments.

Type-4 fractures, in which there are four or more articular fragments.

\section{Data management and analysis:}

The collected data was revised, coded, tabulated and introduced to a PC using Statistical package for Social Science (IBM Corp. Released 2011. IBM SPSS Statistics for Windows, Version 20.0. Armonk, NY: IBM Corp). Data was presented and suitable analysis was done according to the type of data obtained for each parameter.
Table (1): Description of personal and clinical data among all cases

\begin{tabular}{|l|l|c|c|c|c|}
\hline \multicolumn{2}{|c|}{} & Mean & \pm SD & Minimum & Maximum \\
\hline Age & 34.22 & 6.80 & 18.00 & 47.00 \\
\hline \multirow{3}{*}{ Sex } & Female & $\mathbf{N}$ & $\%$ & & \\
\hline & Male & 6 & $14.6 \%$ & & \\
\hline \multirow{3}{*}{ Side of fracture } & Right & 35 & $85.4 \%$ & & \\
\cline { 2 - 7 } & Left & 24 & $58.5 \%$ & & \\
\cline { 2 - 7 } & Bilateral & 3 & $34.2 \%$ & & \\
\hline \multirow{3}{*}{ Laterality of fracture } & Unilateral & 38 & $93.7 \%$ & & \\
\cline { 2 - 7 } & Bilateral & 3 & $7.3 \%$ & & \\
\hline \multirow{2}{*}{ Cause } & Car accident & 13 & $31.7 \%$ & & \\
\cline { 2 - 7 } & Fall from height & 28 & $68.3 \%$ & & \\
\hline Swelling & Yes & 41 & $100.0 \%$ & & \\
\hline Pain and tenderness & Yes & 41 & $100.0 \%$ & & \\
\hline
\end{tabular}

The mean age among study cases was $34.2 \pm 6.8$, with male representing $85.4 \%$ of cases. Right sided fracture was present among $58.5 \%$ of cases, with the majority of cases had unilateral fractures $(93.7 \%)$. Fall from height was the most common cause of fracture $(68.3 \%)$ followed by car accidents (31.7\%). All cases had pain, tenderness and swelling at site of fracture $(100 \%)$

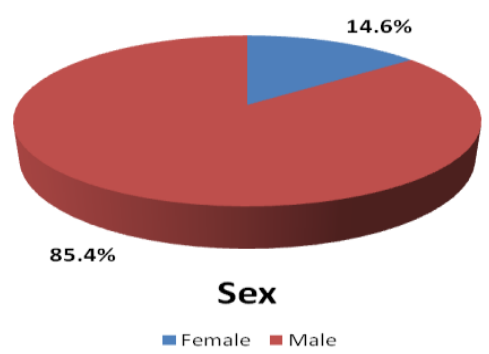

Figure (1): Distribution of cases according to sex.

Table (2): Description of radiological data and mode of treatment among all cases.

\begin{tabular}{|l|l|c|c|}
\hline \multicolumn{2}{|l|}{ Type } & $\mathbf{N}$ & $\%$ \\
\hline \multirow{5}{*}{ Intra articular } & 27 & $61.4 \%$ \\
\cline { 2 - 4 } & Extra articular & 17 & $38.6 \%$ \\
\hline \multirow{5}{*}{ Grade } & Extra articular Type A & 4 & $9.1 \%$ \\
\cline { 2 - 4 } & Extra articular Type B & 6 & $13.6 \%$ \\
\cline { 2 - 4 } & Extra articular Type C & 7 & $15.9 \%$ \\
\cline { 2 - 4 } & Intra articular type I & 5 & $11.4 \%$ \\
\cline { 2 - 4 } & Intra articular Type IIA & 6 & $13.6 \%$ \\
\cline { 2 - 4 } & Intra articular Type IIB & 2 & $4.5 \%$ \\
\cline { 2 - 4 } & Intra articular Type IIC & 1 & $2.3 \%$ \\
\cline { 2 - 4 } & Intra articular Type IIIAB & 7 & $15.9 \%$ \\
\cline { 2 - 4 } & Intra articular Type IIIAC & 1 & $2.3 \%$ \\
\cline { 2 - 4 } & Intra articular Type IIIBC & 1 & $2.3 \%$ \\
\cline { 2 - 4 } & Intra articular Type IV & 4 & $9.1 \%$ \\
\hline & Reach Subtalar and calcaneuocupoid joint & 16 & $36.4 \%$ \\
\cline { 2 - 4 } & Reach Subtalar joint & 11 & $25.0 \%$ \\
\cline { 2 - 4 } & Posterior tuberosity & 7 & $15.9 \%$ \\
\cline { 2 - 4 } & Mid calcaneus body & 4 & $9.1 \%$ \\
\cline { 2 - 4 } & Anterior process & 4 & $9.1 \%$ \\
\cline { 2 - 4 } & Sustenaculum tali & 2 & $4.5 \%$ \\
\hline \multirow{5}{*}{ Management } & Cast & 18 & $40.9 \%$ \\
\cline { 2 - 4 } & ORIF(plate and screws) & 15 & $34.1 \%$ \\
\cline { 2 - 4 } & I fixation by screws & $25.0 \%$ \\
\hline
\end{tabular}

\section{RESULTS}


Table (3): Description of personal and clinical data among intra articular cases

\begin{tabular}{|l|l|c|c|c|c|}
\hline \multicolumn{2}{|c|}{} & Mean & \pm SD & Minimum & Maximum \\
\hline Age & 36.21 & 6.88 & 18.00 & 46.00 \\
\hline Sex & Male & N & $\%$ & \multicolumn{1}{|c|}{} \\
\hline & Female & 0 & $.0 \%$ & & \\
\hline Cause & Car accident & 1 & $4.2 \%$ & & \\
\hline & Fall from height & 23 & $95.8 \%$ & & \\
\hline $\begin{array}{l}\text { Side of } \\
\text { fracture }\end{array}$ & Right & 11 & $45.8 \%$ & & \\
\hline & Left & 10 & $41.7 \%$ & & \\
\hline & Bilateral & 3 & $12.5 \%$ & & \\
\hline $\begin{array}{l}\text { Laterality of } \\
\text { fracture }\end{array}$ & Unilateral & 21 & $87.5 \%$ & & \\
\cline { 2 - 7 } $\begin{array}{l}\text { Pain, } \\
\text { tenderness }\end{array}$ & Yes & 3 & $12.5 \%$ & & \\
\hline Swelling & Yes & 24 & $100.0 \%$ & & \\
\hline
\end{tabular}

Table (4): Description of Radiological data and mode of treatment among extra articular cases

\begin{tabular}{|l|l|c|c|}
\hline \multicolumn{2}{|c|}{} & $\mathbf{N}$ & $\%$ \\
\hline \multirow{3}{*}{ Grade } & Type A & 4 & $23.5 \%$ \\
\cline { 2 - 4 } & Type B & 6 & $35.3 \%$ \\
\cline { 2 - 4 } & Type C & 7 & $41.2 \%$ \\
\hline \multirow{4}{*}{ Site of fracture } & Posterior tuberosity & 7 & $41.2 \%$ \\
\cline { 2 - 4 } & Mid calcaneus body & 4 & $23.5 \%$ \\
\cline { 2 - 4 } & Anterior process & 4 & $23.5 \%$ \\
\cline { 2 - 4 } & Sustenaculum tali & 2 & $11.8 \%$ \\
\hline \multirow{3}{*}{ Management } & Conservative (cast, immobilization) & 10 & $58.8 \%$ \\
\cline { 2 - 4 } & Percutaneous screws fixation & 7 & $41.2 \%$ \\
\hline
\end{tabular}

Table (5): Comparison between intraarticular and extraarticular cases as regard mode of treatment

\begin{tabular}{|c|c|c|c|c|c|c|c|}
\hline & \multicolumn{4}{|c|}{ Type } & \multirow{3}{*}{$\mathbf{P}$} & \multirow{3}{*}{$\begin{array}{c}\mathrm{Si} \\
\mathrm{g}\end{array}$} \\
\hline & & \multicolumn{2}{|c|}{$\underset{\mathbf{r}}{\text { Intraarticula }}$} & \multicolumn{2}{|c|}{$\begin{array}{c}\text { Extra } \\
\text { articular }\end{array}$} & & \\
\hline & & $\mathbf{N}$ & $\%$ & $\mathbf{N}$ & $\%$ & & \\
\hline \multirow{3}{*}{$\begin{array}{l}\text { Managemen } \\
t\end{array}$} & $\begin{array}{l}\text { Conservative(Cast } \\
\text { ) }\end{array}$ & 8 & $29.6 \%$ & $\begin{array}{l}1 \\
0\end{array}$ & $\begin{array}{c}58.8 \\
\%\end{array}$ & \multirow{3}{*}{$\begin{array}{c}0.001 \\
*\end{array}$} & \multirow{3}{*}{ HS } \\
\hline & $\begin{array}{l}\text { Percutaneous } \\
\text { screws fixation }\end{array}$ & 4 & $14.8 \%$ & 7 & $\begin{array}{c}41.2 \\
\%\end{array}$ & & \\
\hline & $\begin{array}{l}\text { ORIF(plate and } \\
\text { screws) }\end{array}$ & 15 & $55.6 \%$ & 0 & $.0 \%$ & & \\
\hline
\end{tabular}

Chi-Square Tests

There was a significant difference between intra articular and extra articular cases as regard mode of treatment, as $55 \%$ of intra articular cases had ORIF compared to $0 \%$ of extra articular cases

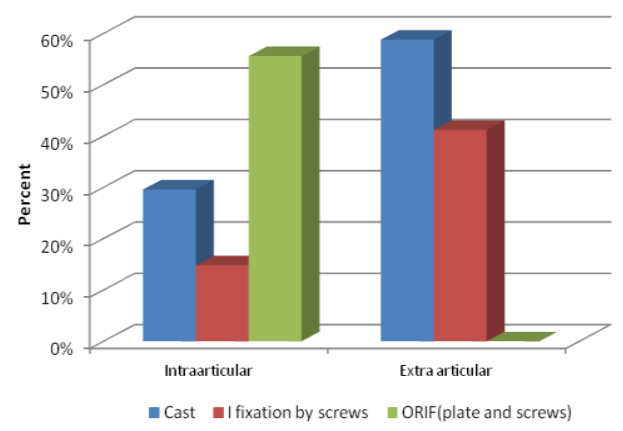

Figure (2): Comparison between intra articular and extra articular cases as regard mode of treatment.

\section{DISCUSSION}

The calcaneus is the largest and most commonly fractured of the tarsal bones. Calcaneal fractures represent only about $2 \%$ of all fractures but $60 \%$ of fractures involving the tarsal bones ${ }^{(\mathbf{1})}$.

Computed tomography has been shown to visualize more accurately the various fracture lines. Some authors believe the advent of CT scanning is the single most important advancement in the management of calcaneal fractures ${ }^{(3)}$.

The coronal CT images evaluate posterior facet involvement, height and width of the calcaneus. Axial CT images can also show the posterior facet, heel varus, and calcaneal widening. Sagittal reconstruction images can help assess the rotational abnormality of the posterior facet fragment, loss of height, and the calcaneocuboid joint ${ }^{(3)}$.

This work included $\mathbf{4 4}$ feet of $\mathbf{4 1}$ patients (three bilateral); 35 males and 6 females, representing $85.4 \%$ and $14.6 \%$ of all patients respectively, their mean age was 34.22 years, we observed that calcaneal fractures commonly occur in male than female which is similar to those found by Ogawa et al. ${ }^{(4)}$.

Fall from height was the most common cause of fracture (68.3\%) followed by car accidents $(31.7 \%)$ This was also stated by Stoller et al. ${ }^{(3)}$, who considered the increased axial load caused by falling from a height and landing on the feet was the most common cause of calcaneal fractures.

Motor car accidents, in which a seated passenger's feet was pressed hard against the floor of the car, became another commonly encountered cause, however, less frequent than fall from height. This was also postulated by Berberian et al. ${ }^{(5)}$.

All cases had pain, tenderness and swelling at site of fracture (100\%).

Intra articular fractures of the calcaneus represent about $75 \%$ of all calcaneal fractures in adults. Several classification systems have been developed, of which the Sanders system is the most commonly used, with several studies having shown this system to correlate with management and $\operatorname{prognosis}^{(2)}$.

In our study multi detector CT calcaneus was done for all cases after suspecting calcaneal fracture either by clinical examination or by conventional radiography, and the patients were 
classified as extra and intra articular fracture according to posterior facet affection. We had 17 patients with extra articular and 27 patients with intra articular fractures representing $38.6 \%$ and $61.4 \%$ respectively which is similar to study done by Schepers who found that one-third of all calcaneal fractures are extra-articular.

In our investigation, classification was established by evaluating axial and coronal images oriented parallel and perpendicular, respectively, to the posterior facet of the subtalar joint as shown on a sagittal MPR image. This evaluation allowed the identification of intra articular fracture lines and the classification of fractures into four types according to the Sanders system.

In this study we found that the type I intraarticular calcaneal fractures were the least $(18.5 \%)$ and the type III was the most frequent (40.7\%), and this finding agreed with Sanders as well as Brunner et al. who stated that type I was uncommon and the other types from type II to type IV were nearly similar in their percentage of occurrence.

The use of computed tomography in the diagnosis of sanders type II and III fractures allows a more adequate surgical planning, which may lead to a better prognosis. With the exception of fractures classified as Sanders I, in which closed treatment can be used, the others have preferentially surgical treatment. Early arthrodesis is formally indicated in type IV fractures. Surgical treatment using osteosynthesis is indicated for the remaining fracture types, II and III ${ }^{(4)}$.

Calcaneocuboid joint involvement in intra articular calcaneal fractures was common and more than half showed sever injuries ${ }^{(6)}$.

In this study 16 cases $(\mathbf{5 9 . 3 \%})$ showed calcaneocuboid joint involvement, all cases with intra articular fracture, they include: $\mathbf{2}$ cases (7.4\%) type II, 10 cases (36.2\%) type III and 4 cases $\mathbf{( 1 4 . 8 \% )}$ type IV, which is nearly similar to those found by Won et al. ${ }^{(6)}$.

This indicates that there is significant correlation between Sanders classification and calcaneocuboid joint involvement, the higher Sanders types the more likely to involve the calcaneocuboid joint.

There was a significant difference between intra articular and extra articular cases as regard mode of treatment, as 55\% of intra articular cases had ORIF compared to $0 \%$ of extra articular cases.

Extra-articular fractures are generally treated in a closed manner. Exceptions include fractures of the sustentaculum tali with displacement of more than $2 \mathrm{~mm}$, posterior avulsion fractures, and significant fractures of the calcaneal body ${ }^{(7,8)}$.

In our study 17 cases extra articular (10 cases) $58.8 \%$ treated conservative and (7cases) $41.2 \%$ treated by minimaly invasive technique using percutaneous screws fixation, 4 cases with unstable fracture calcaneal body and 3 cases of displaced fracture posterior tuberosity.

\section{CONCLUSIONS}

Calcaneocuboid joint involvement in intra articular calcaneal fractures was common and more than half showed severe injuries. We concluded that further studies on the involvement of calcaneocuboid joint should be performed prior to surgical treatment of intra articular calcaneal fractures. Finally, we concluded that, CT assessment is important for excluding articular surface involvement and determining the extent of the fracture. Patients with calcaneal body fractures usually have a better prognosis than those with intra articular fractures, and management is usually conservative. Radiologists must be familiar with injuries of the calcaneus, their anatomy, mechanisms, classification, and implications to help guide the treating physicians.

\section{REFERENCES}

1. Clare MP and Sanders RW (2011): Calcaneus fractures. Unfallchirurg, 114(10): 869-876.

2. Kenneth B, Jose A, Pacheco S et al. (2011): Multidetector CT Evaluation of Calcaneal Fractures. Radio Graphics.RSNA journal ,( 31): 8192.

3. Stoller DW, Tirman PFJ, Bredella M et al. (2004): Ankle and foot, osseous fractures, calcaneal fractures. In: Diagnostic imaging: orthopaedics. Salt Lake City, Utah, Amirsys.

4. Ogawa BK, Charlton TP and Thordarson DB(2009): Radiography versus computed tomography for displacement assessment in calcaneal fractures. Foot \& Ankle International., 30(10): 1005-10. 
5. Berberian W, Sood A, Karanfilian B et al. (2013): CT classification and results of operative treatment .Foot Ankle Clin. , 55 (211): 43-51.

6. Shin WJ, Yang SH and Park HK(2006): Analysis of the Calcaneocuboid Joint Involvement in Intraarticular Calcaneal Fractures. Journal of Korean Foot and Ankle Society, 10(1): 42-7.
7. Zwipp H, Paša L, Žilka L et al .(2016): Introduction of a new locking nail for treatment of intraarticular calcaneal fractures. Journal of Orthopaedic Trauma, 30(3): e88-92.

8. Daftary A, Haims AH and Baumgaertner MR (2005): Fractures of the calcaneus: a review with emphasis on CT. Radiographics , 25(5): 1215-26. 